\title{
Oral Administration of Aqueous Leaf Extract of Ocimum Gratissimum Ameliorates Polyphagia, Polydipsia and Weight Loss in Streptozotocin-Induced Diabetic Rats
}

\author{
OKON U. A. ${ }^{1, *}$, Owo D.U. ${ }^{3}$, Udokang N.E. ${ }^{1}$, Udobang J.A. ${ }^{2}$, Ekpenyong C.E. ${ }^{1}$ \\ ${ }^{1}$ Department of Physiology, College of Health Sciences, University of Uyo, Nigeria \\ ${ }^{2}$ Department of Pharmacology and Toxicology, Faculty of Pharmacy, University of Uyo, Nigeria \\ ${ }^{3}$ Department of Physiology, College of Medical Sciences, University of Calabar, Nigeria
}

\begin{abstract}
The effects of oral administration of aqueous leaf extract of Ocimum gratissimum (OG) on food, water intake and weight changes in streptozotocin (STZ)-induced diabetic Albino Wistar rats was studied. Eighteen rats were randomly assigned into 3 groups of 6 rats each for control, diabetic (DM) and diabetic-treated (DMT) groups. Diabetes mellitus was induced in the test groups (DM and DMT) by a single dose of STZ $(65 \mathrm{mg} / \mathrm{kg}$, i.p.). The extract was administered per oral to the DMT group at a dose of $1500 \mathrm{mg} / \mathrm{k}$ body weight daily for 28 days. All the groups were fed normal rat chow and allowed water freely. The fasting blood glucose levels in the DM and DMT groups were higher $(\mathrm{P}<0.001)$ than the control group, with the DMT group lower $(\mathrm{P}<0.01)$ than the DM group. There was a significant $(\mathrm{P}<0.05)$ loss of body weight in the DM group compared to the control $(\mathrm{P}<0.01)$ and DMT $(\mathrm{P}<0.05)$ groups. There was an increase $(\mathrm{P}<0.01)$ in volume of water taken by the test groups compared to the control. The water intake in DMT group was lower $(\mathrm{P}<0.01)$ than the DM group. The food intake in the DM group was greater $(\mathrm{P}<0.001)$ than the control and DMT groups, with the later higher $(\mathrm{P}<0.05)$ than the control group. We therefore conclude that Ocimum gratissimum reduces blood sugar level in STZ-induced diabetic rats and alleviates the cardinal symptoms of diabetes mellitus namely; polydypsia, polyphagia and weight loss.
\end{abstract}

Keywords Ocimum Gratissimum, Diabetes Mellitus, Polyphagia, Polydipsia, Weight Loss

\section{Introduction}

Diabetes mellitus (DM) is a heterogeneous group of syndromes characterized by an elevation of fasting blood glucose that is caused by a relative or absolute deficiency in insulin[1]. DM is a disease resulting from abnormality in glucose metabolism. Glucose is the major source of energy for the body. Insulin is the hormone secreted by the endocrine pancreas which delivers the sugar to the cells for energy generation and storage. People with DM are unable to produce either enough insulin to turn sugar into usable/storage energy, causing the sugar level to build up in the blood or the cells of the body may develop resistance to the effect of insulin, also resulting in excess blood sugar levels. The earliest and commonest presenting symptoms include: polyuria, polyphagia, polydypsia and weight loss. In DM, due to either absence or resistance to insulin action, glucose cannot move into the cells leading to intracellular glucose starvation. The hallmark of DM is hyperglycaemia which

* Corresponding author:

chairmo2010@rocketmail.com (OKON U. A.)

Published online at http://journal.sapub.org/ajmms

Copyright (C) 2012 Scientific \& Academic Publishing. All Rights Reserved causes blood hyperosmolarity. At normal plasma glucose concentration $(70-100 \mathrm{mg} / \mathrm{dl})$, the filtered glucose is absorbed and none is excreted. In DM, the renal threshold for glucose is exceeded (i.e. plasma glucose concentration is above the $\mathrm{Tm}$ ) and glucose is excreted in the urine. The non-absorbable glucose then acts as osmotic solute in urine, producing an osmotic dieresis (polyuria). This excessive loss of water in urine consequently leads to depletion of ECF volume and dehydration. The thirst centre is activated sequel to the hyperosmotic state resulting in excessive thirst for water (polydipsia). Also, according to the "Glucostat Theory of Feeding Regulation", arteriovenous difference of glucose in the hypothalamus, satiety and feeding centres regulates the feeding response[2]. If the difference is high due to the reason that glucose is more utilized by satiety center, the satiety center is activated. And if the difference is low then feeding center is activated. In DM, glucose cannot move into the cells of the satiety center, thus the arteriovenous difference remains low and the feeing center is chronically active $[3,2]$. This explains the occurrence of polyphagia in DM.

Individuals with untreated DM also experience significant weight loss due to the inability of cells to utilize glucose for energy production, but rather, there is a remarkable activation of the gluconeogenic pathway. The utilisation of muscle 
protein and excessive mobilization of fats from the adipose tissues for energy production in the gluconeogenic pathway accounts for the weight loss in DM. Also, frequent episodes of urination (polyuria) due to hyperglycaemia results in dehydration are a possible cause of weight loss.

Ocimum gratissimum (OG) is a genus of about thirty five species of aromatic annual and perennial herbs and shrubs in the family Lamiacae. It is widely distributed in tropical and warm temperate regions. It is used commonly by the various tribes of Nigeria for nutritional and medicinal purposes. It is called "Nton" in Ibibio/Efik, "Efinrin" in Yoruba, "Daidoya" in Huasa and "Nchonwu" in Igbo. OG is reputed for a number of therapeutic properties including hypoglycaemic [4], antimutagenic activity, antibacterial activity[5], antihelminthic effects, antifungal properties, antidiarrhea effects [5] and anti-convulsant activity[5,4].

Phytochemical analysis of Ocimum gratissimum revealed important constituents as tannins, alkaloids, saponins, flavonoids and phenolic compounds[6]. The plant contains a high percentage of alkaloids and flavonoids ranging from $10.44-14.32$ per cent and $9.28-12.54$ per cent respectively. The volatile aromatic oil from the leaves of this plant consists mainly of thymol (32-65 per cent), eugenol, xanthones, terpenes and lactones[7]. Also citral, ethyl cinnamate, geraniol and linalool have also been extracted from this oil[8]. In 2006, Egesie et al had reported on the safety and the hypoglycaemic action of OG[9].

The prevalence of DM the world over is rapidly assuming a pandemic proportion. The search for a common, most effective, safe, convenient and affordable treatment for DM is unending at the moment. The use of herbal medicinal plants in the treatment of human disease conditions is currently of immense interest to scientists and orthodox medical researchers, as the efficacy of some herbal medicinal plant is no more in doubt. The ability or otherwise of the extract of OG to ameliorate DM induced polyphagia, polydypsia and weight loss will be a further proof of its efficacy as an anti-DM agent. The aim of the study was therefore to investigate the effect of Ocimum gratissimum leaf extract on food, water intake and weight changes in streptozotocin-induced diabetic rats.

\section{Materials and Methods}

\section{Collection and identification of plant materials}

The fresh leaves of Ocimum gratissimum were obtained from the university of Calabar Botanical Garden and were identified by the Chief Herbarium Officer of Botany Department, University of Calabar.

\section{Preparation of aqueous leaf extract of $O G$}

The fresh leaves were rinsed with water to remove sand and debris and then allowed to drip off water. The leaves were then dried under shade for two days and then transferred into Astell Hearson Oven and dried at a temperature range of $40-45^{\circ} \mathrm{C}$.

The dried leaves were then grounded in an electric blender into fine powder to give a gram weight of $527 \mathrm{~g}$. This was soaked in 2.65 liters of water (distilled water) and allowed overnight for about 15 hours and stirred at interval. The mixture was filtered using a satin mesh material and the final filtrate was gotten by using Whatman's filter paper size 1. The final filtrate was dried in the Astell Hearson Oven at $45^{\circ} \mathrm{C}$ to obtain a brown gummy paste. A Mettler P163 electronic weighing balance was used to weigh the gummy paste before stock solution was prepared. The stock solution of the extract was prepared by dissolving $15 \mathrm{~g}$ of extract in $10 \mathrm{ml}$ of water to give a concentration of $1500 \mathrm{mg} / \mathrm{ml}$. The stock solution was labelled appropriately and refrigerated at $4^{\circ} \mathrm{C}$ until required for use.

\section{Phytochemical analysis of $\mathrm{OG}$}

Hundred grams $(100 \mathrm{~g})$ of the powdered plant material was soaked in $500 \mathrm{ml}$ each of distilled water and 99.9 per cent ethanol separately in $1000 \mathrm{ml}$ sterile conical flasks at room temperature for 72 hours. The content was filtered with Whatman No. 1 filter paper. The filtrates were gently evaporated to dryness and then packed in separate clean dry bottles and stored at room temperature until required. The extracts were screened for the presence of carbohydrates, tannins, alkaloids, saponins, phenolics, anthraquinones and cardiac glycosides as described by Trease and Evans (1984) [10] and Sofowora (1984)[11].

\section{Acute toxicity study}

The median lethal dose $\left(\mathrm{LD}_{50}\right)$ of the plant extract was determined by method of Lorke (1983)[12] using 35 rats weighing between $60-100 \mathrm{~g}$. In the first phase, 15 rats were divided into 3 groups of 5 rats each and were treated with the aqueous leaf extract of the plant at dosages of 1000, 1500 and $2000 \mathrm{mg} / \mathrm{kg}$ body weight intra-peritoneally. They were observed for 24 hours for signs of toxicity. In the second phase, 20 rats were again divided into 4 groups of 5 rats each and were also treated with aqueous extract of Ocimum gratissimum at dosages of 3000, 3500, 4000 and $4500 \mathrm{mg} / \mathrm{kg}$ body weight intra-peritoneally. The median lethal dose $\left(\mathrm{LD}_{50}\right)$ was calculated using the second phase.

\section{Experimental Design and treatment of animals}

The rats were weighed and kept in wooden cages of 50 to $80 \mathrm{~cm}$ dimension. They acclimatized for 1 week before the commencement of the experiment. The animals were fed with rat chow and allowed free access to water. Eighteen rats of both sexes were randomly assigned into 3 groups of 6 rats each for control, diabetic (DM) and diabetic-treated (DMT) groups. The experimental procedures involving the treatment and care of animals were conducted in conformity with the approved guidelines by the local research and ethical committee.

\section{Induction of diabetes mellitus}

Diabetes mellitus was induced by a single injection of $65 \mathrm{mg} / \mathrm{kg}$ body weight of streptozotocin. The injection was given intra-peritoneally. The state of diabetes was observed after 48 hours by the symptoms of polyuria and glucosuria and this state was confirmed using uristic test strip (Bayer Health Care LLC, USA). 
The blood glucose level was tested 1 week after induction and at the end of the experiment using a Glucometer (ACCUCHECK Advantage II, Roche Diagnostics ( $\mathrm{GmbH}$, Germany) and ACCU-CHECK Advantage II test strips.

\section{Extract administration and observation}

One week after induction of diabetes, the extract was administered per oral to the DMT group at a dose of 1500 $\mathrm{mg} / \mathrm{kg}$ body weight daily for 28 days. Administration was facilitated by the use of a syringe and Orogastric tube.

\section{Determination of food and water intake}

Water intake was measured using calibrated feeding bottle with stainless steel nozzles. The daily water intake was obtained by subtracting the volume of water remaining at the end of 24 hours of feeding from the initial amount in the water bottle at start of the day. The difference was the amount consumed for the day. The food intake was measured by weighing the amount of food left in the container after 24 hours and subtracting it from the initial amount of food at start of the day's feeding. The food containers were medium sized stainless steel plates to avoid spillage of food.

\section{Weight measurement}

All the rats in the different experimental groups were weighed at the start of the experiment. This was taken to be the initial weight. Weekly weight measurements were taken in all the groups. The final weight measurement was conducted on the last day of the experiment. And the differences in the weight in the various groups recorded accordingly.

\section{Statistical analysis}

All results are presented as mean \pm standard error of mean. Three sets of data were analyzed using one way ANOVA, followed by the least significant difference (LSD) procedure for significant $\mathrm{F}$ values, $(\mathrm{P}<0.05)$ was considered significant. Computer software SPSS and Excel Analyzer was used for the analysis.

\section{Results}

The result of the phytochemical screening is presented in table 1 .

Table 1. Phytochemical screening of the leaf extract of Ocimum gratissimum

\begin{tabular}{|c|c|c|}
\hline Phytoconstituent & Aqueous & Ethanolic \\
\hline Alkaloid & + & + \\
\hline Flavonoid & + & + \\
\hline Tannin & + & + \\
\hline Saponin & + & + \\
\hline Cardiac glycoside & + & + \\
\hline Terpenes and Steroids & + & + \\
\hline Balsam & + & + \\
\hline Renin & + & + \\
\hline Phenol & + & + \\
\hline
\end{tabular}

$$
+=\text { Present }
$$$$
-=\text { Not present }
$$

\section{Toxicity study}

While animals that received very high dosage died, other signs of toxicity were noticed 2 - 4 hours after extract ad- ministration. There were decrease locomotion, writhing, constipation and decreased in sensitivity to touch. Also, there was decreased feed intake and prostration 15 hours after extract administration. The median lethal dose was calculated as follows:

$$
\mathrm{LD}_{50}=\sqrt{\mathrm{D}_{0}} \times \mathrm{D}_{100}
$$

Where $\mathrm{D}_{0}=$ Dosage of 0 per cent mortality

$\mathrm{D}_{100}=$ Dosage of 100 per cent mortality

Thus,

$$
\begin{aligned}
\mathrm{LD}_{50} & =\sqrt{ } 4000 \times 4500 \\
& =\sqrt{ } 18,000,000 \\
\mathrm{LD}_{50} & =4242.64 \mathrm{mg} / \mathrm{kg} .
\end{aligned}
$$

\section{Fasting Blood Glucose}

The mean values of fasting blood glucose in the control, DM and DMT experimental groups were $2.46 \pm 0.192,28.2$ \pm 1.52 and $16.5 \pm 1.21 \mathrm{mmol} / \mathrm{L}$ for control, DM and DMT groups respectively. All the groups were significantly different. The DM and DMT groups were significantly higher $(\mathrm{P}<0.001)$ than the control. The DMT group was significantly lower $(\mathrm{P}<0.01)$ than the DM group. (Fig. 1).

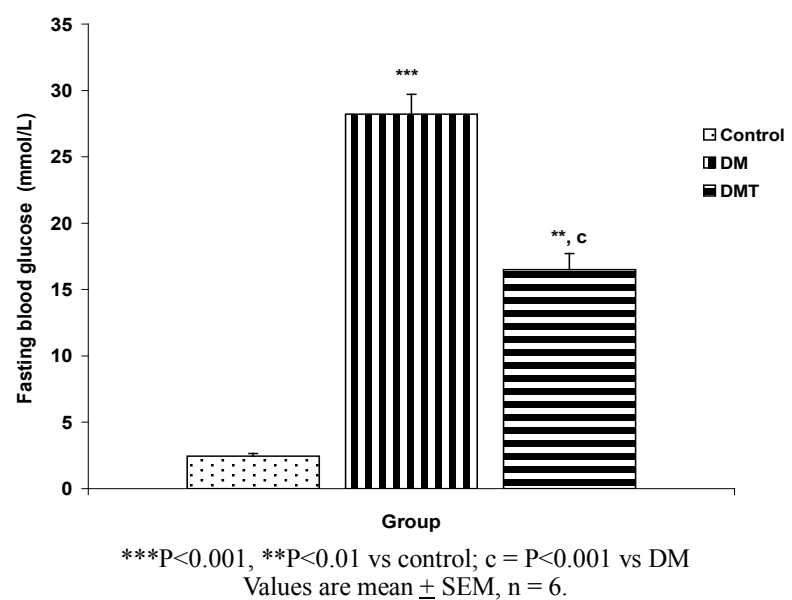

Figure 1. Fasting blood glucose in the control, DM and DMT experimental groups of rat

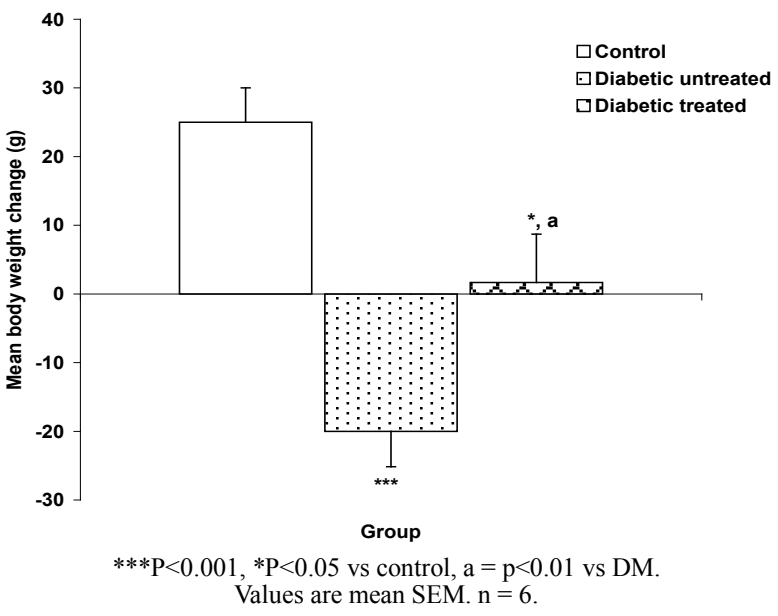

Figure 2. Mean body weight change of the different experimental groups

\section{Body Weight Changes}

The mean body weight changes in the control, DM and DMT experimental groups of rats were: $10.0 \pm 7.7,-3.3 \pm$ 1.10 and $4.33 \pm 0.67 \mathrm{~g}$ for control, DM and DMT groups 
respectively. There was significant $(\mathrm{P}<0.05)$ loss of body weight in the DM group compared to the control $(\mathrm{P}<0.05)$ and DMT $(\mathrm{P}<0.01)$, Fig. 2. The control showed a greater increase in body weight when compared with the DM group.

\section{Daily Food Intake}

The mean daily food intake per rat fed on control, diabetic (DM) and diabetic-treated (DMT) groups were $8.146 \pm 0.168$, $11.862 \pm 0.272,8.944 \pm 0.259 \mathrm{~g}$ respectively. There was significant difference between the groups. The food intake in the DM group was significantly $(\mathrm{P}<0.001)$ higher than the control and DMT groups. The food intake was significantly higher in the DMT group compared to the control $(\mathrm{P}<0.05)$, as shown in Fig.3.

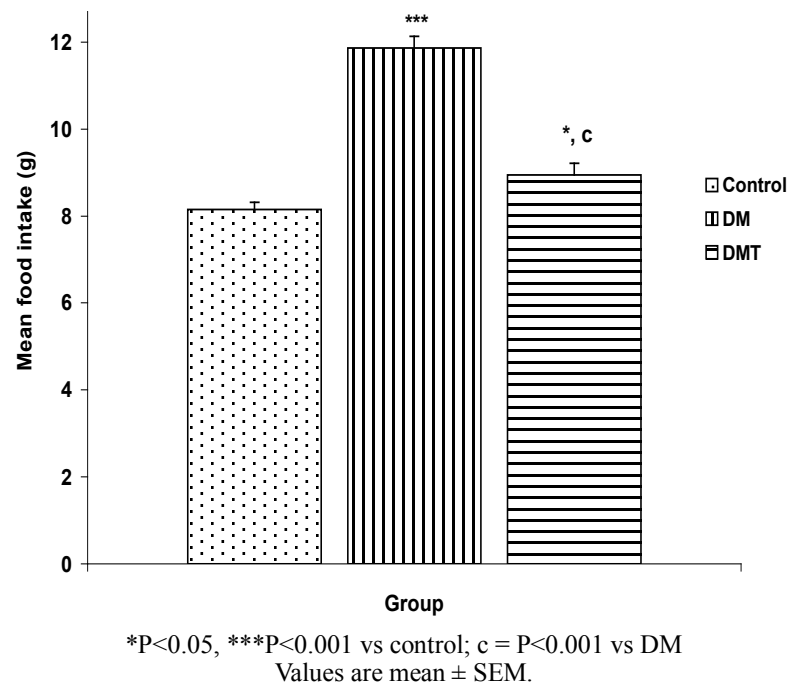

Figure 3. Comparison of mean food intake of the different experimental groups

\section{Daily Water Intake}

The mean daily water intake per rat for the control, DM and DMT were $8.213 \pm 1.757,15.577 \pm 1.462$ and $11.192 \pm$ $0.700 \mathrm{ml}$ respectively. There was significant $(\mathrm{P}<0.01)$ increase in volume of water taken by the test groups compared to the control. The DMT group was significantly $(\mathrm{P}<0.01)$ lower than the DM group, as shown in Fig.4.

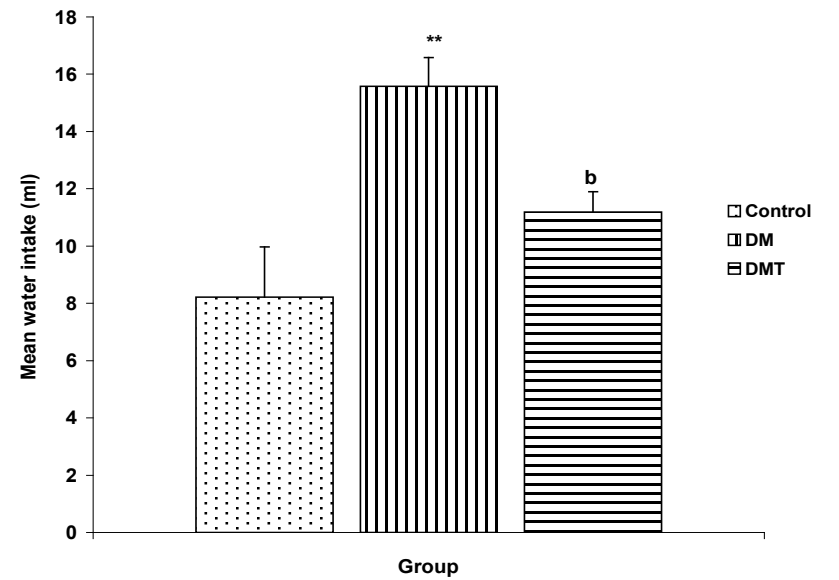

$* * \mathrm{P}<0.01$ vs control; $\mathrm{b}=\mathrm{P}<0.01$ vs $\mathrm{DM}$

Values are mean \pm SEM.

Figure 4. Comparison of mean water intake of the different experimental groups

\section{Discussion}

The result of the phytochemical screening of the aqueous leaf extract of Ocimum gratissimum showed no major differences in the phytochemical constituents from the results of other previous investigations. Saponins, flavonoids, alkaloids, phenol, renin, balsam, terpenes and steroids, tannins and cardiac glycosides were found to be present[6].

Tannins have been reported to act on proteins to form protective layer on mucus membranes[13]. Flavonoids have been found to have membrane stabilizing properties and also affect some process of intermediary metabolism and inhibit lipid peroxidation in different systems[14]. Phenols have antioxidant properties which carry out their protective activity on cells either by preventing the production of free radicals or by scavenging free radicals produced in the body $[15,16]$. Almost all the phytoconstituents of OG confirmed in this study are known to influence biological system activities.

The median lethal dose was calculated to be $4242.6 \mathrm{mg} / \mathrm{kg}$ body weight. A dosage of $1500 \mathrm{mg} / \mathrm{kg}$ body weight of the aqueous leaf extract of $\mathrm{OG}$ was administered per oral to the test groups. No animal died following the administration of the dose used for the study. Egesie et al, (2006) had earlier administered a dosage of $250-1500 \mathrm{mg} / \mathrm{kg}$ body weight to achieve a dose dependent blood glucose reduction in STZ-induced diabetic rats[9].

Estimation of the blood glucose levels for the control, diabetic (DM) and Diabetic treated (DMT) experimental groups confirmed hyperglycemia in the test groups (i.e. DM and DMT), thus suggesting that the insulin - producing pancreatic beta cells were destroyed by streptozotocin (STZ) administered for the induction of DM in these groups. Other studies had also reported the hypoglycaemic effect of OG. Aguiji et al, (2000) and Egesie et al, (2006) have both reported the efficacy of OG in lowering the blood glucose level in STZ - induced diabetic animals[17,9]. Though treatment with the aqueous extract of $\mathrm{OG}$ did not return the blood glucose level to normal when compared to the control group, the level of reduction was significant when compared with the diabetic control group.

Polyphagia, polydipsia, polyuria and weight loss are established classical symptoms and signs of DM. These were clearly demonstrated in this study, with increased food and water intake in the test groups (DM and DMT), and also marked weight loss in these groups compared to the control. It is evident from our findings that OG ameliorated significantly these classical symptoms of DM. There was a significant reduction in the quantity of food and volume of water intake in the DMT group when compared to the DM group. These findings suggest that $\mathrm{OG}$ affects the neuroendocrine regulation of food intake by the GI system, including nutrient sensing and peptide secretion by enteroendocrine cells. Despite substantial fluctuations in daily food intake, Granner (1996)[18] had reported that glucosuria causes a substantial loss of calories for every gram of glucose excreted, and that this loss when coupled with loss of muscle 
and adipose tissues, results in severe weight loss in spite of increase in appetite.

Animals maintain a remarkable stable body weight because; the overall caloric ingestion and expenditure are exquisitely matched over long periods of time, through the process of energy homeostasis[19]. The brain receives hormonal, neural and metabolic signals pertaining to body energy status and in response to these inputs, coordinates adaptive alterations of energy intake and expenditure. To regulate food consumption, the brain must modulate appetite, and the core of appetite regulation lies in the gut-brainaxis[19]. Furthermore, signals from the GIT are important regulators of gut motility and satiety, both of which have implications for the long term control of body weight[20].

The hyperglycemia of DM gives rise to glycosuria (blood sugar exceeding the renal threshold for glucose) followed with osmotic diuresis (Polyuria). The latter in turn causes water depletion, which trigger signals to the thirst centre for increased water intake. A vicious cycle of polyuria gives rise to polydypsia, the degree of which is a function of the level of hyperglycemia. The aqueous leaf extract of OG significantly reduced the magnitude of food intake, water intake and weight loss in the diabetic treated group compared to the diabetic group. Since food and water intake are controlled by centres in the hypothalamus, it is conceivable that OG affects these centres. For instance, suppression of food intake is a function of the satiety centre in the ventromedial hypothalamus and, water intake is influenced by osmoregulators in the anterior hypothalamus that sense the osmolality of the body fluids. Therefore, OG may be stimulating the satiety centre while inhibiting the thirst centre (osmoreceptors) as well as hunger centre (lateral hypothalamic nuclei).

\section{Conclusions}

Our study has clearly demonstrated that OG reduces the blood sugar level in STZ-induced diabetic rats and ameliorates the cardinal symptoms of polydipsia, polyphagia and weight loss.

\section{REFERENCES}

[1] Champe, P.C., Harver, R.A., Ferrier, D.R. (2008). Diabetes Melittus in Lippincott's Illustrated Reviews Biochemistry ( $4^{\text {th }}$ edition). London. Pp. $337-348$

[2] Guyton, A. C. \& hall, J.E. (2006). Textbook of Medical Physiology. Philadelphia: W.B. Saunders

[3] Gannong, W.F. (2006). Review of Medical Physiology, 21st Edition. California: Lange Medical Publications

[4] Aguiyi, J.C., Obi, C.I., Gang, S.S, \& Igweh, A.C. (2000). Hypoglycaemic activity of Ocimum gratissimum in rats. Fitoterapia 71(4): 444-446

[5] Orafidiya, O.O., Elujoba, A.A., Iwalewa, F.O. \& Okeke, I.N.
(2000). Evaluation of antidiarrhoeal properties of Ocimum gratissimum volatile oil and its activity against enteroagregative Eschrichia coli. Pharmacology Letters 10: 9-12

[6] Afolabi, C., Akinmoladun, E. O., Ibukun, I., Emmanuel, A., Obuotor, E. M. \& Farombi, E.O. (2007). Phytochemical constituent and antioxidant activity of extract from the leaves of Ocimum gratissimum. Scientific Research \& Essay 2 (5):163-166

[7] Ezekwesili, C.N., Obiora, K.A., \& Ugwu, O.P. (2004). Evaluation of Anti-Diarrhoeal property of Crude Aqueous Extract of Ocimum gratissimum L.(Labiatae) in Rats. Biokemistri Nigerian Society for Experiment Biology 16(2): $122-131$

[8] Sulistiarini, D.L., Oyen, P.O. \& Ngugen, X.D. (1999). Ocimum gratissimum L. In: Plant Resource of South-East Asia. No.19: Essential oil Plants. Prosea Foundation. Bogor Indonesia. $140-142$

[9] Egesie, U.G., Adelaiye, A.B., Ibu, J.O. \& Egesie, O.J. (2006). Safety and hypoglycaemic properties of aqueous leaf extract of Ocimum gratissimum in streptozotocin induced diabetic rats. Nigerian Journal of Physiological Sciences 21(1-2): $31-35$

[10] Trease, G.E., \& Evans, W.C. (1984). Trease and Evans' Pharmacognosy: A Physician's Guide to Herbal Medicine. 13th Edition, Bailliere Tindall London

[11] Sofowora, L.A. (1984). Medicinal plants and traditional medicine in Africa. Spectrum Books Ltd, Ibaban. 85-82

[12] Lock, U. C. (1983). Determination of Lethal Dose of xenobiotics in experimental animals. Nature 45: 264-266

[13] Wilard, I. (2002). Encyclopedia of Herbs. 21: 112 - 119

[14] Alanko, J., Riuffa, A., Holm, P., Mulda, I., Vapatalo, H., \& Metsa-Ketela, T. (1999). Modulation of Arachidonic acid Metabolism by plants: Relation to their structure and antioxidant /per-oxidant properties. Free Radical Biology and Medicine 28(suppl 1-2): 193-201

[15] Oboh, G. \& Rocha, J.B.T.(2007). Polyphenol in Red Pepper (Capsicum annuum var. aviculare [Tepin]) and Their Protective Effect on Pro-oxidant Induced Lipid Per oxidation in Rat Brain and Liver. European Food Reserve Technology 225: $239-247$

[16] Oboh, G. (2006). Blanching on the Antioxidant Property of Some Tropical Green Leafy Vegetables. LWT- Food Science Technology 38:513-517

[17] Aguiyi, J.C., Obi, C.I., Gang, S.S, \& Igweh, A.C. (2000). Hypoglycaemic activity of Ocimum gratissimum in rats. Fitoterapia 71(4): 444-446

[18] Granner, D.K. (1996). Hormones of the pancreas \& gastrointestinal tract. In Murray, R.K., Granner, R.K., Mayes, P.A. \& Rodwell, V. W. (Eds). Harpers Biochemistry $24^{\text {th }}$ edition, (pp. 586 -587). Connecticut: Appleton and Lange

[19] Cummings, D.E. \& Overduin, J. (2007). Gastrointestinal regulation of food intake. Journal of Clinical Investigations 117(1): 13-23

[20] Drucker, D.J. (2007). The role of gut hormones in glucose homeostasis. Journal of Clinical Investigation 17(1): 24-32 